\title{
Marketing the resilient city image for sustainable development. Examples from Rotterdam and Thessaloniki.
}

Theodore Metaxas' ${ }^{1}$, Stella Psarropoulou ${ }^{2}$ *

1 Department of Economics, University of Thessaly, Volos, Greece; metaxas@uth.gr

2 Department of Operational planning, Urban Resilient Observatory, Municipality of Thessaloniki, Greece; s.psaropoulou@thessaloniki.gr

* Correspondence: metaxas@uth.gr Tel.: +3024210 74917

\begin{abstract}
The focus of this study is to identify whether resilience and sustainable development can be used as an image for strategic planning of the city marketing. Resilience is about building and planning for future proof the cities. How urban challenges and crisis have the lowest impact and the maximum of bounce back and evolution. Resilience is part of the sustainable development. Thus, it is important for the decision-makers to define the mission on their strategic planning in a holistically way taking into consideration the basic assets of a city, the environment, the economy and the society and how can all of them can be combined to marketing the city and take into consideration the internal and external environment. As the past few years' city marketing has become an important tool for the urban development. The main goal is to show how city marketing can be applied on a city that tries to be more resilient and more sustainable by using strategic urban planning to set the vision, to identify the challenges and the problematic areas and to set new goals and objectives in order to plan and build to future proof the complexity of an urban system. For answering the questions of this article we use two case studies Rotterdam (Netherlands) and Thessaloniki (Greece), using a literature review and researches conducted alongside with a benchmarking of their resilient strategies as both of the cities are members of the Resilient Cities Network. From a different perspective of resilient thinking, both of the cities have managed to use resilience as a marketing image for further sustainable development.
\end{abstract}

Keywords: place marketing; sustainable development; resilience; image;

\section{Introduction}

Urbanization is nowadays an international phenomenon with a rising rate. According to UN HABITAT, in 1990, 43\% of world's population lived in urban areas but it is expected to reach $80 \%$, in 2050. Shlomo Angel [1] smart phrased it as the "Planet of cities". Territorials and urban areas encompass a plethora of socio-economic activities and they generate around $80 \%$ of the world's GDP. Specifically, in Europe, the $70 \%$ of residents inhabit in urban areas, while they generate the two thirds of the Europe's GDP [2]).Regions and cities are in the front line the past twenty years as engines of development and innovation. However, mostly, regions and cities cope with challenges and chronic stresses as poverty, economic and social inequality, climate change and pandemics that affect to urban dwellers but also to the infrastructure and the basis urban fabric. Thus, in recent years the interest in sustainable development as a broader umbrella on urban planning and on resilience has been raised in scholar discourse. Sustainable development encompasses economic development with social cohesion and integration with the respect of the quality and function of the environment [3]. Additionally, the notion of resilience is now quite widespread in urban planning and thinking. In many documents, it is not just mentioned but also described (i.e. HABITAT III, EU Urban Agenda, Leipzig Charter etc.) and it applies in many researches and scientific areas. During the pandemic of COVID-19, urban resilience is more in the frontline as a process of mitigation, adaptation and recovering from all the unprecedented yet impact. Thus, resilience is about building and planning for future proof the cities. It is a process and it represents a new way of thinking, scoping on 
how urban challenges and crisis have the lowest impact and the maximum of bounce back, bounce forward and evolution. Resilience is one of the concepts of sustainable development [4], or moreover "sustainability is an essential goal for development, and resilience a way of thinking and acting that would lead us towards achieving sustainability [5]. On the other hand, within this constantly changing world regions and cities compete with each other for tourists, investors, companies, well-informed citizens or even for specific target groups [6]. Thus, the role of city marketing has been increased and the modern world mostly seeks to the image. In the regime of technological development, digital transformation, social media and digital marketing, image should be a political concern or a mission [7]. Consequently, city marketing has become an important tool for the urban development [8], and this paper aims to show how city marketing can be applied on a city that tries to be more resilient and more sustainable and uses strategic urban planning to set the vision, to identify the challenges and the problematic areas. In addition to set new goals and objectives in order to plan and build to future, proof the complexity of an urban system. At the first section, we focus on the marketing as a tool for urban planning and the characteristics needed to be applied on a city's context. While, thereafter, we try to acknowledge the notions of resilient and sustainable development and how these two notions can identify the image of a city. Looking at international and European urban experiences we will pass to two examples by literature review, researches conducted the recent years, and we attempt a slight benchmark on their resilient thinking implementation and image making. The paper tries to show the interconnection between city marketing and the resilient and sustainable urban development by trying to answer the following questions: a) how can resilient and sustainable urban development contribute to the marketing image of a city?, b) can city marketing strategies constitute strategies for resilience and sustainable development and vice versa? In addressing those questions we need to point out also that the image of a region/city is the result of the coordination and identification of different target groups internally and externally too, by considering the image as a "good" [9].

\section{Image and City marketing}

In this constantly changing era of digitalization, social media and more comfort communication, the modern world focus mostly on image [10]. Starting with the image building and the identity creation, we move forward to define the role of the city's marketing. Within the process of regional and urban competition, regions and cities are seeking to improve their images internally but also externally in order to advance their competences, develop the tourism business, attract investors and international contacts, or attract funding and financial sources and to make the region/city sustainable and resilient to live in.

If we consider the region/city as a "productive system", then the image should be the "productive good". Additionally, each region/city should be considered as a complex system with many aspects and interconnections with the internal and external environment and ecosystem services.

Moreover, as a complex system the region/city should take into consideration the following aspects, regarding to building up its image [11]:

a) Each region/city has its internal and external environment. The internal environment embodied all the strengths and weaknesses, chronic stresses and challenges and it includes the local policies and governmental priorities along with the community of the region/city thus the entrepreneurs, civil society, local stakeholders and entities but mostly the citizens. On the other hand, the external environment consists all the socio-economic factors that can enhance the region/city's competences or put it in development pathways.

b) Each region/city has its own specific characteristics that originate by the history or the cultural heritage, the economic id and its natural sources. Other characteristic such as the geographic position, the financial situation, the link to Academia or the social inclusion could also define the particularities of a region/city, the amount of complexity and 
interactions and create the competitive advantages. Nevertheless, each of those characteristics is also unique and needs to be developed or enhanced or improved through a strategic process.

Accordingly, the customers decide upon a region /city's image and upon the trust built on it, too. That can be justified as image is more or less the identification of the citizen, the reputation and the impact or the acceptance of it and thus, the customer of a place-product will receive at the end a trustworthy relation based on successful results or in the improvement of the quality of life [12]. Thus, city marketing is the tool that promotes the characteristics of a place and facilitates the development process.

City marketing can be considered as a functional and managerial tool, but at the same time a planning, strategic and operational process for defining a region's/city's vision, goals and objectives and the way to implement in order to raise the efficiency and the competences. The focus of course is on the city marketing as a strategic planning process that includes the internal and external assets of a region /city's system. As Piskoti et al. mention (12, pp.3-4):

"City Marketing is the promotion and communication of exploration and realization of competitive strength, comparative advantages and forces of attraction in order to achieve multisided economic and welfare objectives (Piscoti etc.2002)"

Consequently, city marketing sets the vision and the development strategic goals of a region/city depending on the particularities and those competitive advantages in order to promote and to be efficient [13]. Furthermore, the strategic planning is stronger when it does not only comply with the direct performance of the region/city, but also with the performance and the activation of all the assets of the region/city, including local authorities, stakeholders, organizations and the civil society. Thus, the identification plays a key role on strengthening the "brand" and the competences. Zenker et al. [14], present a model where the identification of residents is raised within a more complex system by using urban prototypes:"(...) a high prototype complexity can increase perceived fit and the feeling of belonging". Therefore, city marketing and strategic planning should encompass not only the characteristics of the city, but also how these characteristics profound the identification of the citizens and set optimal goals to attract target groups that could also identify and allow the region/city to develop.

However, how the city marketing complies with the urban planning and the resilient and sustainable development? The question can be defined on how a strategy of city marketing complies with a sustainable or a resilient urban strategic plan. Dril et al. [15] propose two basis steps for a city marketing strategy. Firstly, a SWOT analysis that sets the goals and development priorities and in the second, establish working groups with the stakeholders and setting up the communication mechanisms and tools.

On the other hand, a strategy that focus on the sustainable and resilient way of thinking includes urban planning holistically under the three pillars, environment, society and economy. A first comment could be that urban planning and the cultivation of sustainable development and resilient thinking can contribute to marketing [16] and defining the parameters or enhances the co-creation and participatory process that perhaps could strengthen the identification of the citizens and the attractiveness of the place along with the future proof and with the respect on the natural sources and the ecosystem services.

\section{Sustainable development and resilience}

\subsection{Sustainable development}

The notion of sustainable development was first mentioned in 1987 by the World Commission on Environment and Development and it was defined as "the development that meets the needs of the present without compromising the ability of future generations 
to meet their own needs." [17,18]. After almost 40 years of the world's summits from Stockholm to Nairobi to Rio and to Johannesburg, the notion of sustainable development has a broader meaning and it indicates now more a necessary condition 18] and a way of acting. The basic principles of the sustainable development are the interconnections between the environment, the economic growth and the social cohesion as pillars on the decision-making process and policies. Coming to 2015 where the UN, within the framework of the Urban Agenda (HABITAT III) launched the 17 Sustainable Development Goals with a numerous of indicators to be measured. The SDGs could be considered as an international prototype of the sustainable development adapted to the unique characteristics, weaknesses and strengths on a national, region and local level. That's the reason why sustainable development could be identified as a broader comprehensive concept that comprises the ecological, economic and social dimensions and conducts with other notions or designations such as the "resilient" city, the "eco" city, the "smart" and "intelligent" city and the "knowledge" city and so on [19]. Jeffrey Sachs [20], on his book "The age of sustainable development", which was adopted by the UN General Assembly, describes and analyses the perspectives and the principles of sustainable development, in the light of the SDGs. For Sachs (pp. 20-23), sustainable development is "both a way of understanding the world and a method for solving global problems" and he supports and a fourth objective or pillar, which is governance. Additionally, to environment, social cohesion and economy, governance plays a key role to the complexity of the system of the sustainable development. As a complex system though, it is normal not to expect to have one solution to every problem. And that's mostly the answer to those who believe that sustainability and resilience are just buzzwords. The complexity of a system provokes many misinterpretations along with the difficulty to pass from academic basis to practical implementation [21]. For example when a bank failed in 2008 the whole world faced an unexpected economic crisis with multiple effects. Meaning, that a complex system demands a complex way of thinking. Although, sustainable development can also be considered as the tool to prototype and set a normality that brings well-being to citizens. It is not an easy task neither on international, nor on national or local level [22]. Consequentially, urban sustainability arises from this normative and in order to address sustainable development, it needs a holistic approach, urban planning but mostly engagement of the local government and the local community (stakeholders and civil society) [23]. Coming to the questions of this article on what is the connection between the sustainable development and city marketing, it has been regarded from a literature review that although there is an academic research interest $[24,25,26]$, although it hasn't been outlined a common perspective or models or strategic methodology of how sustainable development could also be embedded to city's marketing plan and image. According to Kamińska [27, p.33] "sustainable marketing" indicates how the goals of sustainable development embedded with the factors of marketing and suggests that sustainable marketing should be considered a key principle to the strategic and operational urban planning from the local authorities and stakeholders. Moreover, for example, discussing about the governmental administration in Poland's cities and counties, Kamińska proposes several requirements that need to include as prototypes on strategic documents and promote the combination of sustainability and city marketing. Concluding to the inference that sustainable marketing may not give direct solutions, but it should be considered precisely more as an effort to stimulate small scale interventions in urban and environmental policies and economic and social indicators. Smaller scale interventions may then address effects in a macro level "ensuring the development and existence of future generations [27 p.40]. At the same concept, Taecharungroj et al. [28] illustrate that the environmental perspective of the sustainable development seems to be more commonly used referring to the image and a city's marketing. But sustainable development is divided to three pillars, environment, economy and social cohesion. With their study, Taecharungroj et al. (p.210) proposed a tool for branding a place by fostering sustainability and economic development, and they assessed as case study ten towns in the vicinity of Bangkok. According to their tool that 
implemented on these ten cities with no economic efficiency and resources for a marketing strategic plan and they were analyzed from various aspects, the place branding and sustainability connect by displaying the differentiate aspects of the sustainability as a brand position (p.224). Although the results of their research face some limitations and further research is needed, it provides a robust on the interface of sustainability and place branding and indicates that Mayors and local authorities should consider multiple aspects when comes to the strategic and operational urban planning. Positively, sustainable development could be unambiguous and could be as key principle to develop comparative advantages according to the prerequisites and characteristics of each city. Additionally, city or place marketing aforementioned is not used only to attract tourists, but also plays an important role in urban planning and economic development, the social cohesion through the identification on the residents, the environmental sustainability and the position in international relations [29]. Another interesting case study on Liverpool and the effects of a mega event during the European Capital of Culture 2008, examines how place branding impacts on the robustness of sustainable development (p.203). The impact of such an event facilitated in Liverpool, economic growth, social integration and environmental sustainability (p.210). All of the three bottom lines of sustainable development. Thus, place marketing could be the key driver to deliver sustainable development, as long as each region/city assess and finds the unique competences that interconnect with the factors of sustainable development (p.210). A more generic approach is preferable but we should consider that every place needs to embrace its uniqueness.

\subsection{Resilience}

Profoundly during the unprecedented regime that pandemic of COVID-19 brought along, the crisis is more and more an often occasion happening. As such, cities have to cope with multiple crisis, beyond the chronic stresses and the socio-economic inequalities. Thus, sustainability and resilience define a process where the regions/cities need to future proof the urban fabric and the urban dwellers, with the respect of the natural resources and target to economic growth and social harmony. This goal, simultaneously with the enrichment of the competitive advantages of a place and the competences that could evolve and prepare, mitigate and better adapt future crisis and shocks in a more resilient way. Nevertheless, sustainable development could be considered as the broader concept that embeds different other concept according the era, the circumstances and the localities of a place, such as resilience. The Circles of Sustainability, that P. James introduces in his book, "Urban Sustainability in Theory and in practice" [30], puts sustainability in the core of the urban complex system, which interacts with other junctures such as resilience, adaptation, livability etc. who are looking forward in a prosper social life (p. 10). Consequently, this approach indicates that we need to develop tools seeking to interrelate and allow to plan and design better and to embed all the new trends and aspects of the social life (p.11). For example, Copenhagen has managed to enhance the attention and the investment as the first carbon neutral capital city in the world and to amplify her image on that. Similarly, coalitions such as the Covenant of Mayors or the Compact of Mayors, with a network of cities and the participation of their political leaders can help them induce attention and investments and urge differentiate target of groups [31]. Accordingly, the notion of resilience is not another concept to replace sustainability but is another concept that needs to intersect with the sustainable development, the urban planning and the image of a region/city. Nevertheless, resilient is more than ten years now in the scholar discourse and widespread in urban thinking and planning [32]. Many different definitions have been given with a diversity of scientific approaches. Some academics think that resilience is a buzzword as there is an ambiguous transformation from theory to practice [33] or there is no consensus on the common principles and methodologies in order to measure the progress on resilience [34]. Resilience is mostly related to climate change and environmental perspective (EU perspective), or in risk reduction (America's perspective) [35], 
but yet resilience imposes in many scientific areas and it is commonly accepted as a concept and a way of thinking that imposes on the "global mandate of urban competiveness and has a more urgent and consensual character" [36]. Coming from the Latin word "resiliere", which means rebound and retreat [37], academic literature claims two perspectives of resilience, the "bouncing back" and the "bouncing forward" [38]. That explains as well why resilience may answer on different scientific areas. Beginning as a notion on the psychology, where resilience is the ability to recover from a shock. On the other hand, under an ecological framework, Walker et al. [39] define resilience as "the capacity of a system to absorb disturbance and reorganize while undergoing change so as to still retain essentially the same function, structure, identity, and feedbacks". That is claimed to be the engineering perspective, according to which in a stable ecosystem (region/city), if a shock or a crisis occur then the system tends to bounce back to an equilibrium situation. On the opposite, under the ecological perspective, the ecosystem (region/city) following a crisis or a shock, comes to another state and impacts on ecosystem's (region/city) behavior [40]. Nevertheless, the aforementioned two perspectives of resilience cannot be applicable on urban planning and functions because, cities are complex and dynamic systems with multiple interconnections among the urban ecosystem and assets [41]. Simmie and Martin [42] claimed an evolutionary approach of the resilience with direct field of application on regional and urban economy. According to their research, urban systems are complex and dynamic that embed all the socio-economic life and tend to be affected, adapt and cope with all the stresses and challenges that arise from economic forces, technological transformation and environmental provocations. Simmie and Martin support their research on the interface of the notion of economic resilience with adaptation and they provoke four concepts that enhance the evolutionary perspective of economic resilience. Walker et al. [43] also defines four aspects of resilience: Latitude, Resistance, Precariousness, Panarchy, but Simmie et Martin [44] distinguish them as followed:

1) The Generalized Darwinism, which emphasizes on innovation and diversity.

2) The "path dependencies" in which decision and policies based on ethics and historic continuity.

3) The complexity theory, which focuses on self-organization.

4) The panarchy adaptive model, which intersects resilience with adaptation.

Moving forward, they suggest the panarchy adaptive model as the most preferable to explain the evolution perspective of economic resilience. The panarchia is described by the model of the adaptive cycles of Holling [45], which demonstrates that all the assets of a regional/urban economy (entities, entrepreneurs, local authorities), are constantly alter and adaptive on their environment, while economic development encompasses growth and competitive conditions. That points out also that every sector or asset of an urban system passes the adaptive cycle's phases at different period and each one has different resilience. Under this case, resilience it is considered more as a process rather than a characteristic of a place [46]. Going to another perspective the notion of resilience was primary mention due to hurricane Katrina (New Orleans, USA) and then created linkages to climate change (mitigation and adaptation), social inclusion and the economic crisis [47]. Thus, many cities try to develop resilient strategies or adopt tools and methods that could enhance their resilience thinking way and the planning and in order to structure new urban policies. Several organizations and initiations of cities' networks have been established to robust the resilience thinking process and to aim cities and regions to exchange knowledge and technical assistance [48]. Those are ICLEI, the Asian Cities Climate Change Resilience Network (ACCCRN), the Resilient Cities Network and other initiatives. Table 1 depicts definitions given by the international city networks. 
Table 1. Definitions of the notion of resilience according to international city networks

\begin{tabular}{ll}
\hline Title 1 & \multicolumn{1}{c}{ Title 2} \\
\hline & "A resilient city is prepared to absorb and recover from any \\
shock or stress while maintaining its essential functions, struc- \\
tures, and identity as well as adapting and thriving in the face of \\
continual change. Building resilience requires identifying and as- \\
sessing hazard risks, reducing vulnerability and exposure, and \\
lastly, increasing resistance, adaptive capacity, and emergency \\
preparedness"
\end{tabular}
"The capacity of individuals, communities, institutions, busi-
nesses, and systems within a city to survive, adapt, and grow no
matter what kinds of chronic stresses and acute shocks they ex-
perience"

RESILIENT CITIES NETWORK

1.ICLEI [49], 2.RCN [50]

Overall and with the last definitions of resilience, we need to justify the aforementioned literature review and how this answers the questions of this paper. More important is to clarify that resilience has multiple meanings. However, it cannot mean everything. It has also a theoretical approach under the ecological framework and a theoretical attempt to be applied on socio-economic systems as cities [51]. But this application isn't unproblematic because as Davoudi [52] points out "in applying an ecologically rooted concept to the social setting, we need to tread carefully and ensure that in trying to understand society through the lens of ecology we do not lose the insights from critical social science».

Adding also that we have argued that cities are complex adaptive systems [53]. Summing up, the concept of resilience is more or less a way of thinking that requires effective and smart application on each city's fabric, specific characteristics, needs and values. Taking for example all the work provided the past six years by the Resilient Cities Network (pioneered from 2014 by Rockefeller Foundation) to the members-cities of different sizes, history, culture, needs and stage of development world widely, we can surely understand that resilience is not just and on-off procedure. Nevertheless, a process that allows each city to develop a strategic plan that could allow to respond, adapt and evolve under unprecedented circumstances, uncertainty and constant transformations of its ecosystem. Resilience provides to decision-makers a way of working, cooperating and interconnect either at institutional level or at social level [54].

Nevertheless, Davoudi [55] indicates a cautionary note on the resilience theory, suggesting that there is thin dividing line not to become resilience a buzzword but she argues that the impact of resilience in urban planning is substantial because it can shape the challenges and also respond to them. Finally, Walker and Salt [56] suggest a three-step framework to understand the resilient thinking. The first step is to asses and understand how world works (or how a specific city works). The second one, to understand that the system of a city is complex adaptive system and last step is the willingness and the initiatives taken to improve the adaptability and transform and evolve the city's system through collaborative and targeted-based processes [57].Consequently, the resilience has diverse parameters and can be applied in many sectors of a city's life. In addition, by making a first attempt to answer the questions posed on this paper, as resilience interrelates with urban planning and yet in a substantial way, it could be punctual to assume that indeed interfaces with city marketing and can be used to enrich, promote or enhance the image of a region/city. Perhaps not as an overall "resilient city" concept but maybe in specific sectors. This can be indicated in the next section by providing a few examples from cities that tried to establish the resilient way of thinking and working and it was resulted positively to their image and economic development. 


\section{Examples from Rotterdam and Thessaloniki}

As mentioned before, resilience can be applied in many different scientific fields but for an urban complex system, resilience is defined as the way an urban ecosystem reacts and maintained to a disturbance, adapts but also transforms and evolves in all aspects. Therefore, resilience includes spatial planning, urban development and adaptation and interrelates with all the components of an urban system such as environment, economy and society [58,59]. Thus, resilience is embedded in the sustainable development concept. While trying to answer the questions posed in this article, we use some examples from literature review that explains how resilience can become an image for the marketing of a city. Therefore, we use the example of Rotterdam (Netherlands) and Thessaloniki (Greece). The latest was chosen due to author's personal professional experience and knowledge. However, both of the cities are members of the Resilient Cities Network and they have developed and been implementing their resilience strategy. Although the examples are not products of a direct research procedure, however they were chosen as the most representative to justify some of our questions and perspectives upon this article's main point.

\subsection{Rotterdam}

Accordingly, Peiwen Lu and Dominic Stead [60] on their paper indicate how resilience strategies are implemented and what the impact from theory to practice is. They use as a case study the city of Rotterdam (Netherlands), from the perspective of adaptation in climate change. Rotterdam is one of the most vulnerable to flooding city of Netherlands because it is a Delta city of Rhine-Meuse-Scheldt and the Europe's largest seaport. Rotterdam is the second biggest city of Netherlands with 651.446 population, but it influences more than 2 million in a region level along with The Hague. Rotterdam's economy relates a lot with the water [61]. Rotterdam, in its resilient strategy, defines resilience as a virtue of their residents because they are quite familiar to the notion of resilience, as they "were known for their vision, strength, courage and persistence" [6262]. Rotterdam has managed several times to make water cases an opportunity and to be promoted as a climate adaptation living hub. However, their resilience strategy acknowledges also other stresses and puts the municipality in a more holistic approach including economic development and the civil society. Whilst, strategic urban planning for climate adaptation and especially in flooding, have been developed since the mid-2000s, with this resilient strategy, Rotterdam's decision-makers wanted to suffuse holistically and to consider also chronic stresses and impacts on the economic and social life of this city. As mentioned to the strategic document [62]:

"Resilience thinking is being incorporated in the policymaking and initiatives across all domains of city government, including across social, physical and economic programmes. These elements come together in "The Story of the City". The resilience strategy and "The Story of the City" are complementary. The latter sets out the kind of city we want Rotterdam to be, the Resilience Strategy shows how we can achieve this in a resilient way".

However, as Peiwen Lu and Dominic Stead [63] report on their article and research, planners and decision-makers of the municipality eager to make the climate risk of the water an opportunity to enhance economic development and to promote the city as a climate adaptation pioneer and best practice to follow or invest. Moreover, local authority's policies advance Rotterdam's competitiveness using as an image the based-climate readiness, strategic planning and adaptation on flood risks. An example that interconnects the image with the resilience thinking in Rotterdam was the Floating pavilion that used as an example to promote the city in the 2010 Shanghai World Expo. Even more, in the Resilience Strategy [64] is mentioned that the past fourteen years "Rotterdam has won international acclaim for its work on climate adaptation." Specific spatial cases and examples have gained 
a position on international press as it promotes Rotterdam to specific target groups as an engineering and climate based knowledge city. Another example is the Water squares that used by the Rotterdam's decision-makers in order to promote an exchangeable technical knowledge to other cities. Water squares built on 2013 under the context of Rotterdam water city 2035 program and it is actually a useful open space that it can also restore rainwater during downpours [65]. The Water Squares are an example of climate-based solutions on urban planning with a resilient perspective which it encompasses also an economic and social activity (figure 1).

Concluding, we should point out that Rotterdam has been using its expertise on climate change and foster the resilient thinking and to enhance its image. Many other examples could examined in the future, regarding to the city-port relation and the urban regeneration that is being held under 'The Stadshavens' project. In addition, how it has affected the marketing image of the city or the 'BoTu' project that demonstrates the first resilient neighborhood that targets to diverse group of residents (Figure 2). That indicates that many Rotterdam's initiatives try to remark resilient thinking through climate based solutions and puts it as a pioneer and expertise for other cities, creating a marketing image and a competitive advantage as well as a main competence [66].

Figure 1. Water Squares-Rotterdam

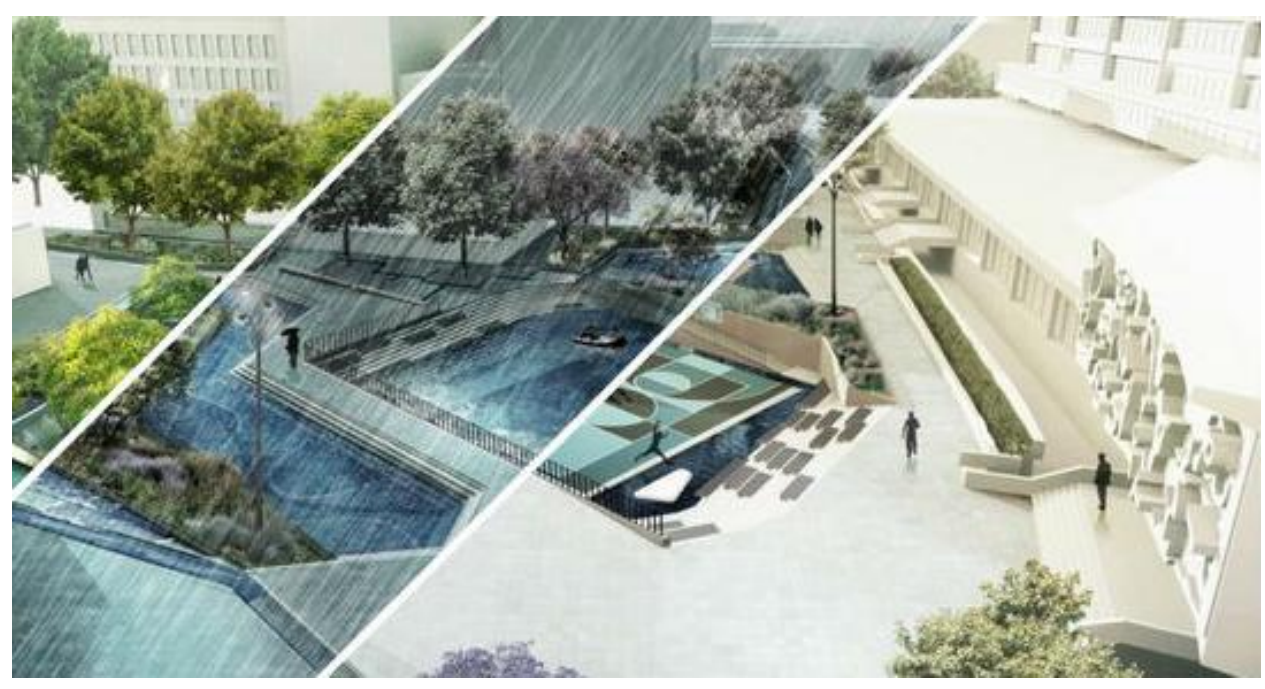

(source:https://www.rinnovabili.it/bozze/water-squares-piazze-dacqua-attirano-la-pioggia-564/)

Figure 2. Bo.Tu project-Rotterdam

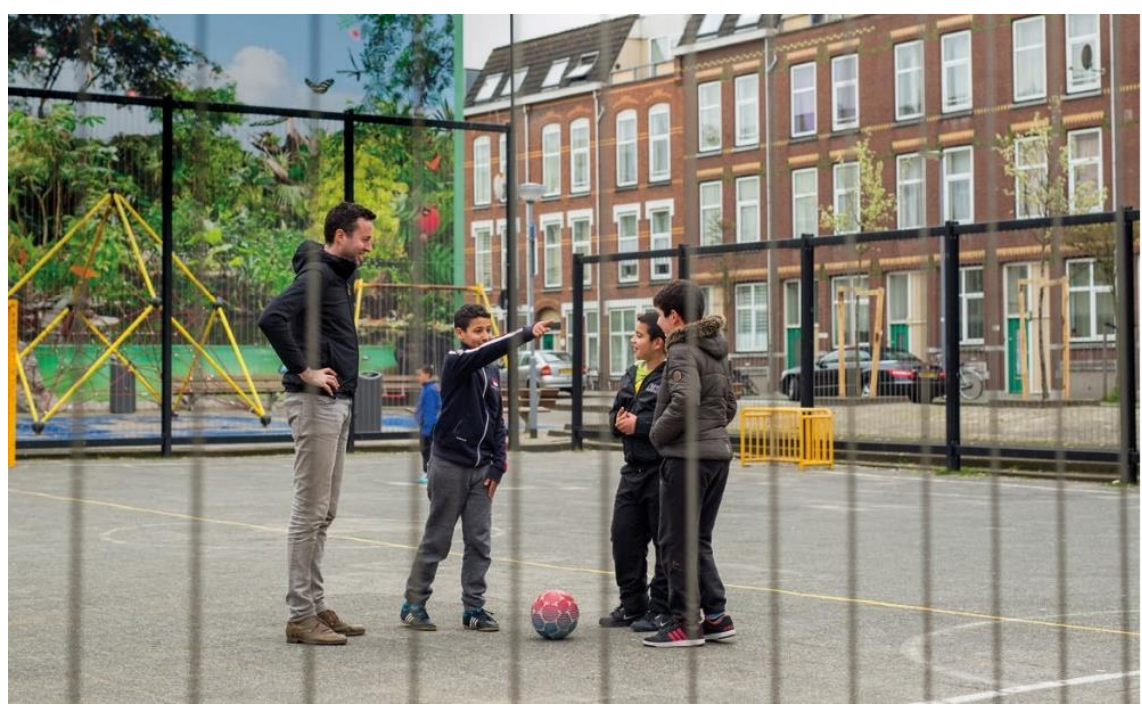


(source: https://resilientcitiesnetwork.org/urban_resiliences/rotterdam-social-cohesion/)

\subsection{Thessaloniki}

Unlike Rotterdam, Thessaloniki does not have a long history on urban planning and resilient thinking. Thessaloniki is also a second-tier port city, the second biggest city in Greece, with a 2.300 years' history. Municipality's population is 324,766 people (2011 census), although it is considered to influence the whole region of Central Makedonia and approximately 1,9 million people. Thessaloniki has a multicultural rich history. With a growing tourism the last eight years and differentiate actions by the urban managers, Thessaloniki seeks a position within the competitive European and international arena of the cities. However, the Municipality of Thessaloniki for many years lacked of the economic, social and political elite that could embrace the city's structure, and dynamic id in order to activate and advocate policies and strategic goals in a more European and international perspective [67]. In order to be understandable the governmental context of Thessaloniki we should clarify the existing governmental apparatus. Thessaloniki until the ‘90s was in a development trajectory with a robust industry and a cosmopolitan identification. However, and due to different chronological conjectures, in the early 90s and until present, Thessaloniki experiences times of recession whilst it tries to discover its competitive advantage and the basis competences. Additionally, Thessaloniki used to experience many conservative tensions that could not allow the city to robust and seek for an extroverted perspective and vision by the urban managers. Consequently, Thessaloniki faced locked-in path dependencies that intensified by the economic crisis of 2008 and its unprecedented the future consequences of the present pandemic of Covid. Alongside, the governmental system in Greece is centralized and municipalities have to operate under a very strict and quite limited or disjointed circumstance. Therefore, the municipalities in Greece face financial restrictions and difficulties and they need to focus and to find alternative funding sources, turning into European Union. Although, the management of European funds stops at higher administrative levels (regions or Ministries) and the local authorities have restricted options of development schemes or projects. However, the need for funding addressed the development of urban strategies after 2010 [68].

Coming back to Thessaloniki, a longitude research conducted by Pitidis and Coaffee [68] from the beginning of the municipality's resilient journey on 2014 until present. Into their research, they developed a methodology in contrast to the methodological tools advanced by Rockefeller Foundation and the collaboration with Arup during the 100 Resilient Cities initiative- the City Resilience Framework [69]. The difference with Rotterdam was that Thessaloniki had to fight with many problematic situations starting with a governmental apparatus rigid and conservative. Main challenge of the city is the conflict jurisdictions, the lack of cooperation across the other governmental levels or the civil society, consolidated operational and structural silos of the stakeholders of the city. The most important fostered also by the economic crisis, was the lack of trust by citizens on the governmental operational goals and the denial of any participation [70].

Therefore, urban managers in Thessaloniki did not have any familiarity with the concept of resilience in 2014. Thus, the strategy developed and implemented, was the first attempt of the city to embed the resilience thinking within the context of the city and to build up a new way of working trying to cope with many chronic stresses and disoperation of the past. The 100RC methodology provided to the municipality an innovative model for the local authority to develop a holistic city strategy whilst more than 40 organizations and 2000 citizens participated. The conduction of the Preliminary Assessment, by pointing out 
common strengths and weaknesses of the city and later to the development of the Strategy “Thessaloniki 2030", launched in March 2017 [71].

Trying to benchmark Rotterdam's and Thessaloniki's past in resilience thinking we should definitely result that they are two different perspectives that are influenced by the complexity of each city but mostly by the past experiences of the urban management and governmental function. Thus, Thessaloniki tried to embed the resilience thinking and moving from rigid individual practices per sector to adopting a holistic approach and bringing participatory planning as a key principle to future design the city and seek for a sustainable and resilient development [72]. According to the first Deputy Mayor for Urban Resilience of the municipality: "in a city that is constantly changing, this strategy represents the start of a process of co-creation. A way to collectively work together, sharing responsibility, resources, opportunities and results" [73]. Although it is quite interesting the resilient journey of Thessaloniki, this article's purpose is to identify interconnections between resilience and the marketing image of the city. Moreover, we chose Thessaloniki because it actually managed to reinforce city's image -again like Rotterdam- as a city who took an opportunity through the participation in an international cities network, to establish new way of working and to transform the governmental status quo by giving the city a new mission, to become more resilient. Targeted to encompass the resilient thinking within the city's fabric "which depicted the operational and attitudinal changes stimulated by municipal officials engaging with resilience-thinking, and which are capable of shaping a novel and innovative governance delivery future for Thessaloniki" [74] and to increase the competiveness and attraction of the city to the international and European audience. A primary example implemented during the operation of the Resilient Thessaloniki office that aided to emerge Thessaloniki's image, was the cooperation with the World Bank in three main projects that contributed to the institutionalization and establishment of the resilient thinking. The first one was the development of a masterplan for the redevelopment of the waterfront pointing out projections under the three pillars of sustainable development, economic (and financial), environmental and societal. The second and third were two projects that provoked resilience as a substantial asset to risk reduction and risk management. Building upon a continuity plan for emergency cases and an Open Risk data platform allowed citizens and stakeholders or local entities to connect with the municipality's operations and planning in an effort to reinforce awareness and preparedness on extreme events. Figure 3 depicts an event for 20 June, in memorial to the catastrophic earthquake of 1978 in Thessaloniki.

Figure 3. $20^{\text {th }}$ of June 2017 -Resilient Day event

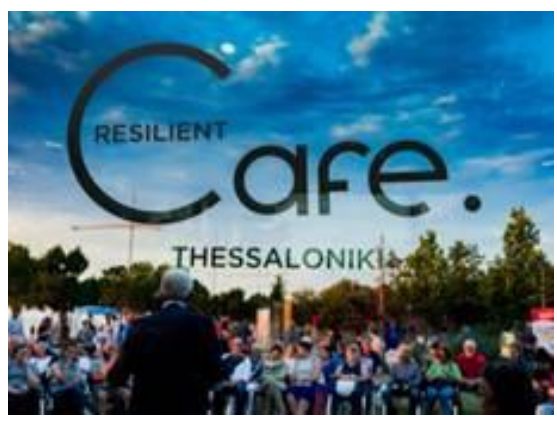

(source: Resilient Thessaloniki office archive)

Another example from the implementation process was a three-day international meeting (CoLab) conducted and funded by the 100RC and the municipality for the redevelopment of the Egnatia corridor after the construction of Metro (Figure 4,5,6). It was one of the first 
international meetings with specific thematic but holistic representation of forty participants of local and international institutions (e.g. Academia), firms (e.g. CISCO) and entities (e.g. REAL ESTATE) to share a common vision and discuss innovative solutions and ideas for the redevelopment and refurbish of the central corridor of the city.

Last example was the Youth resilient challenge, an initiative of a NGO, the United Societies of Balkans, leaders on youth empowerment and voluntarism with the main purpose of the cooperation with the Municipality of Thessaloniki and the Resilient office was to "raise the youth aspect in the process of making Thessaloniki a resilient city and to ensure that young people's voices but also their role and responsibility are embedded in such process" [75].

Figure 4,5,6. Colab June 2018-City Hall Thessaloniki
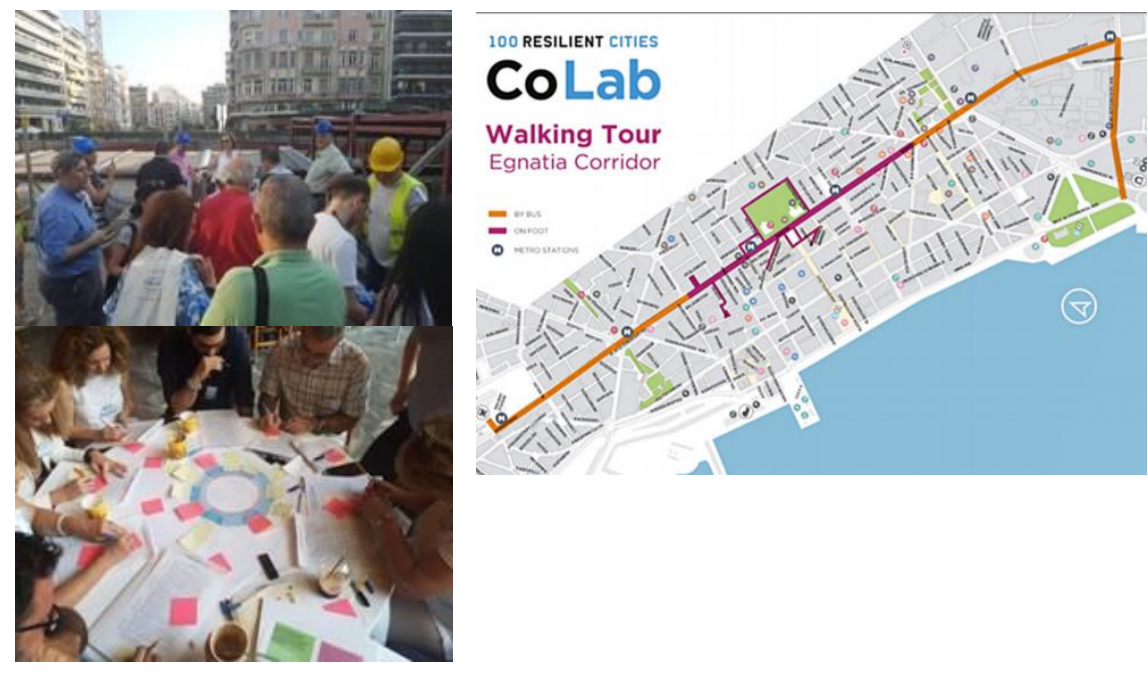

(source: Resilient Thessaloniki office archive)

Of course, many other examples could be mentioned, but the resilient thinking is not a destination for Thessaloniki, is an ongoing process. Through all these years, Resilient Thessaloniki managed to gain a position in national and international press and to attract the funding and the technical assistance of international or European institutions to help it incorporate urban development. As reported in World Bank's blog: "Thessaloniki's strategy provides a roadmap for cities to make revitalization projects happen, from concept to implementation and financing" [76]. Additionally, Municipality of Thessaloniki managed to ensure a loan direct from the European Investment Bank to foster projects with a sustainable and resilient impact. Further to this collaboration was given to Thessaloniki the opportunity to use the advisory hub (Technical assistance) of the European Commission in order to be subsided with two feasibility studies for specific goals and objectives of the Strategy "Thessaloniki 2030". It was also included a video filmed by the EIB officers for the promotion of these projects and the municipality as a destination.

Summing up, Resilient Thessaloniki begun because of the participation in the 100RC network and its mission was to develop a resilient strategy but moreover to establish and institutionalize the resilient thinking within the city's context. During the period, 20142019 a lot of events, workshops and actions were conducted that contributed to the enhancement of the image of the city. The Resilient Strategy "Thessaloniki 2030" has been 
used as a case study to many academic and research scholars $[77,78,79]^{1}$ and municipality of Thessaloniki as a site visit for many European Universities. But, answering the questions posed in this article, the resilient concept aided the image of the city of Thessaloniki as a paradigm of governmental transformation to more participatory procedures, embed resilience thinking and adaptability cross-departmental, cross-governmental and between civil society of the city. As Pitidis and Coaffee [80] result:

"Thessaloniki's success in transforming entrenched governance traditions through the implementation of urban resilience should provide an example for other cities to proceed with further engagement of citizens in the decision making processes (...) to avoid returning to the prior state on institutional inertia".

Thus, Thessaloniki tries to move to a new model of working by establishing synergies and collaborative trends with the civil society and so, it promotes an image of a resilient, youth, multicultural and inclusive European city [81].

\section{Conclusions}

In this article we made an effort to clarify and point out the interrelations between place marketing and a place's image with the notions of sustainable development and resilience. Although there is not an extent literature review and further researches need to be conducted on the interconnections or the need of interrelation between resilience and place marketing under the umbrella of sustainable development, we tried to answer specific questions and to simplify all the keywords in order to find the connecting links with the urban development.

More specifically, as place marketing plays a key role nowadays for the urban management of a place should be considered as a functional and managerial tool, but at the same time a planning process. Thus, city marketing and strategic planning should encompass the characteristics of the city alongside with the components that allow and provoke the identification of the citizens and can attract various target groups. Moving further to the notion of sustainable development, we came to a conclusion that sustainable development should be considered an umbrella that embeds different other concept according the era, the circumstances and the localities of a place, such as resilience as a concept. Whilst resilience is substantial in urban planning and the urban managers not only to cope with the uncertain and chronic stresses and universal urban challenges, but also to 'bounce forward' and to future proof the places [82,83]. We used the two examples Rotterdam and Thessaloniki as an aftermath of a literature review, existing researches with specific perspective and by the author's professional occupation. We pursued a light benchmarking on how their image has been upraised while embedded the resilience thinking into the city's context. Further research with a specific framework should be conducted to identify the interconnections between resilience discourse and branding as a result or because of the participation in global cities' networks such as Resilient Cities Network. Especially after the pandemic regime, resilience shall play a key role in discourses of cities and in strategic planning and shall encompass all the tensions that could reinforce a city's image fostering an overall sustainable development.

Author Contributions: Conceptualization T.M.; methodology (case study) S.P.; validation, S.P.; investigation, S.P.; resources, S.P.; writing-review and editing, T.M- S.P.; supervision, T.M.;

\footnotetext{
1 Resilient Thessaloniki office's collaborations with the local University and Academics, manifested the establishment of a master program in 2018, in "Spatial planning for sustainable and resilient development", in the Department of Planning and Development of Aristotle University of 
Funding: This research received no external funding

Conflicts of Interest: The authors declare no conflict of interest.

\section{References}

1. Kourtit, K. (2014). Planet of Cities, by Shlomo Angel. 2012. Cambridge, MA: Lincoln Institute of Land Policy. $341+x v i$. Journal of Regional Science, 54(1), 161-162

2. Medeiros Eduardo, Zwet Arno van der, "Sustainable and Integrated Urban Planning and Governance in Metropolitan and Medium-Sized Cities", Sustainability, 2020

3. Gibbs D. C., J.Longhurst, C. Braithwaite, “Struggling with sustainability': weak and strong interpretations of sustainable development within local authority policy", Environment and Planning A 1998, volume 30, pages 1351 -1365

4. llgen, S.; Sengers, F.; Wardekker, A. City-To-City Learning for Urban Resilience: The Case of Water Squares in Rotterdam and Mexico City. Water 2019, 11, 983

5. Philip Harrison, Kerry Bobbins, Christina Culwick,Tracy-Lynn Humby, Costanza La Mantia, Alison Todes and Dylan Weakley, “Urban Resilient thinking for municipalities”, University of the Witwatersrand, Gauteng City-Region Observatory, 2014, p.15

6. Zenker Sebastian; Petersen Sibylle, "Resident-City Identification: Translating the Customer Relationship Management Approach into Place Marketing Theory", Conference paper, 50th Congress of the European Regional Science Association: "Sustainable Regional Growth and Development in the Creative Knowledge Economy", 19-23 August 2010, Jönköping, Sweden.

7. Dril N., Galkin A., Bibik N., "Applying city marketing as a tool to support sustainable development in small cities: case study in Ukraine", 2nd International Conference “Green Cities-Green Logistics for Greener Cities", 2-3 March 2016, Szczecin, Poland, ELSEVIER, Transportations Research Procedia 16 (2016) 46-53

8. Deffner A., Metaxas T., "Is City Marketing Opposed to Urban Planning? The Elaboration of a Pilot City Marketing Plan for the Case of Nea Ionia, Magnesia, Greece", 46th CONGRESS OF THE EUROPEAN REGIONAL SCIENCE ASSOCIATION ‘Enlargement, Southern Europe and the Mediterranean' August 30th- September 3rd 2006, University of Thessaly, Department of Planning and Regional Development, Volos, Greece

9. Metaxas T., "The image of the city as 'good': the creation of a city's promotional package through a strategic framework analysis of city marketing procedure", Transactions on Ecology and the Environment vol 67, 2003

10. Dril N., Galkin A., Bibik N., “Applying city marketing as a tool to support sustainable development in small cities: case study in Ukraine", 2nd International Conference “Green Cities-Green Logistics for Greener Cities", 2-3 March 2016, Szczecin, Poland, ELSEVIER, Transportations Research Procedia 16 (2016) 46-53

11. Metaxas T., "The image of the city as 'good': the creation of a city's promotional package through a strategic framework analysis of city marketing procedure", Transactions on Ecology and the Environment vol 67, 2003, pp 429

12. Piskóti Istvan, Szabolcs Nagy, "Identity and Image in the City Marketing”, Conference: VII. International Congress on Public and Nonprofit Marketing, Szeged, Hungary, June 2008

13. Deffner A., Metaxas T., "Is City Marketing Opposed to Urban Planning? The Elaboration of a Pilot City Marketing Plan for the Case of Nea Ionia, Magnesia, Greece", 46th CONGRESS OF THE EUROPEAN REGIONAL SCIENCE ASSOCIATION ‘Enlargement, Southern Europe and the Mediterranean’ August 30th- September 3rd 2006, University of Thessaly, Department of Planning and Regional Development, Volos, Greece

14. Zenker Sebastian; Petersen Sibylle, "Resident-City Identification: Translating the Customer Relationship Management Approach into Place Marketing Theory", Conference paper, 50th Congress of the European Regional Science Association: "Sustainable Regional Growth and Development in the Creative Knowledge Economy", 19-23 August 2010, Jönköping, Sweden, p.9 
15. Dril N., Galkin A., Bibik N., "Applying city marketing as a tool to support sustainable development in small cities: case study in Ukraine”, 2nd International Conference “Green Cities-Green Logistics for Greener Cities”, 2-3 March 2016, Szczecin, Poland, ELSEVIER, Transportations Research Procedia 16 (2016) p.48

16. Deffner A., Metaxas T., "Is City Marketing Opposed to Urban Planning? The Elaboration of a Pilot City Marketing Plan for the Case of Nea Ionia, Magnesia, Greece", 46th CONGRESS OF THE EUROPEAN REGIONAL SCIENCE ASSOCIATION ‘Enlargement, Southern Europe and the Mediterranean' August 30th- September 3rd 2006, University of Thessaly, Department of Planning and Regional Development, Volos, Greece

17. Amundsen, Eirik S. and Asheim, Geir (1991): The Notion of "Sustainable Development". Published in: The Nordic Journal of Environmental Economics, Vol. 2, (November 1991): pp. 10-14.

18. M.M. Shah, "Sustainable Development", Editor(s): Sven Erik Jørgensen, Brian D. Fath, Encyclopedia of Ecology, Academic Press, 2008, Pages 3443-3446, ISBN 9780080454054

19. Martin de Jong, Simon Joss, Daan Schraven, Changjie Zhan, Margot Weijnen, "Sustainable-smart-resilient-low carboneco-knowledge cities; making sense of a multitude of concepts promoting sustainable urbanization", ELSEVIER, 2015, Journal of Cleaner Production 109 (2015) 25-38

20. Sacks Jeffrey D., "The Age of Sustainable Development”, Columbia University Press, NY, 2015

21. Chelleri Lorenzo, Aliaksandra Baravikova, "Understandings of urban resilience meanings and principles across Europe", ELSEVIER, Cities 108(2020) 102985, 2020

22. Sacks Jeffrey D., “The Age of Sustainable Development”, Columbia University Press, NY, 2015, pp.29-33

23. Sacks Jeffrey D., “The Age of Sustainable Development”, Columbia University Press, NY, 2015 p. 388

24. James P., “Urban Sustainability in Theory and Practice”, Routledge, NY 2015

25. Maheshwari Vishwas, Ian Vandewalle and David Bamber, "Place branding's role in sustainable development", Journal of Place Management and Development, Vol. 4 No. 2, 2011, pp. 198-213

26. Taecharungroj Viriya, Morakot Muthuta, Pheereeya Boonchaiyapruek, "Sustainability as a place brand position: a resident-centric analysis of the ten towns in the vicinity of Bangkok", Place Branding and Public Diplomacy (2019) 15:210228

27. Lukasiewicz-Kamińska Agnieszka, "SUSTAINABLE CITY MARKETING: A MODERN MANAGEMENT MODEL”, NR 867 PROBLEMY ZARZĄDZANIA, FINANSÓW I MARKETINGU NR 402015 pp. 33-42

28. Taecharungroj Viriya, Morakot Muthuta, Pheereeya Boonchaiyapruek, "Sustainability as a place brand position: a resident-centric analysis of the ten towns in the vicinity of Bangkok", Place Branding and Public Diplomacy (2019) 15:210228

29. Maheshwari Vishwas, Ian Vandewalle and David Bamber, "Place branding's role in sustainable development", Jour-nal of Place Management and Development, Vol. 4 No. 2, 2011, pp. 198-213

30. James P., "Urban Sustainability in Theory and Practice”, Routledge, NY 2015

31. Kanuri Chaitanya, Aromar Revi, Jessica Espey \& Holger Kuhle, “Getting Started with the SDGs in Cities”, 2016, available: https://www.researchgate.net/publication/309417493_Getting_Started_with_the_SDGs_in_Cities_A_Guide_for_Stakeholders

32. llgen, S.; Sengers, F.; Wardekker, A. City-To-City Learning for Urban Resilience: The Case of Water Squares in Rotterdam and Mexico City. Water 2019, 11, 983

33. Chelleri Lorenzo, Aliaksandra Baravikova, "Understandings of urban resilience meanings and principles across Europe”, ELSEVIER, Cities 108(2020) 102985, 2020

34. Salata Konstantina-Dimitra, Yiannakou Athena, “The Quest for Adaptation through Spatial Planning and EcosystemBased Tools in Resilience Strategies", SUSTAINABILITY, 2020 
35. Chelleri Lorenzo, Aliaksandra Baravikova, "Understandings of urban resilience meanings and principles across Europe”, ELSEVIER, Cities 108(2020) 102985, 2020

36. Athanassiou E., Kapsali M., Karagianni M., "Green” and resilient: shaping a new identity for Thessaloniki, Conference: International Conference on Changing Cities 2: Spatial, Design, Landscape \& Socio-economic Dimensions", At: Porto Heli, Peloponnese, Greece, 2015

37. Tóth Balázs István," Regional economic resilience: concepts, empirics and a critical review", MISCELLANEA GEOGRAPHICA - REGIONAL STUDIES ON DEVELOPMENT, Vol. 19, No. 3 ,2015, pp. $70-75$

38. Chelleri Lorenzo, Aliaksandra Baravikova, "Understandings of urban resilience meanings and principles across Europe”, ELSEVIER, Cities 108(2020) 102985, 2020, p.2

39. Walker Brian, C. S. Holling, Stephen R. Carpenter, and Ann Kinzig, "Resilience, Adaptability and Transformability in Social- ecological Systems", 2004, available: http://www.ecologyandsociety.org/vol9/iss2/art5

40. Tóth Balázs István," Regional economic resilience: concepts, empirics and a critical review", MISCELLANEA GEOGRAPHICA - REGIONAL STUDIES ON DEVELOPMENT, Vol. 19, No. 3 ,2015, pp. 70-72

41. Fernandes José Rio, Chamusca Pedro, “Urban policies, planning and retail resilience”, ELSEVIER, 2012 p.170-177

42. Simmie James and Martin Ron, "The economic resilience of regions: towards an evolutionary approach", Cambridge Journal of Regions, Economy and Society 2010, 3, 27-43

43. Walker Brian, C. S. Holling, Stephen R. Carpenter, and Ann Kinzig, "Resilience, Adaptability and Transformability in Social- ecological Systems", 2004, available: http://www.ecologyandsociety.org/vol9/iss2/art5, p.2

44. Simmie James and Martin Ron, "The economic resilience of regions: towards an evolutionary approach", Cambridge Journal of Regions, Economy and Society 2010, 3, pp.31-35

45. Holling C.S., "Understanding the complexity of Economic, Ecological, and Social Systems”, Ecosystems (2001) 4: 390-405

46. Simmie James and Martin Ron, "The economic resilience of regions: towards an evolutionary approach", Cambridge Journal of Regions, Economy and Society 2010, 3, pp. 41-42

47. Martin de Jong, Simon Joss, Daan Schraven, Changjie Zhan, Margot Weijnen, “Sustainable-smart-resilient-low carboneco-knowledge cities; making sense of a multitude of concepts promoting sustainable urbanization", ELSEVIER, 2015, Journal of Cleaner Production 109 (2015) pp.25-38

48. llgen, S.; Sengers, F.; Wardekker, A. City-To-City Learning for Urban Resilience: The Case of Water Squares in Rotterdam and Mexico City. Water 2019, 11, 983 p.2

49. ICLEI, “RESILIENT CITIES, THRIVING CITIES: THE EVOLUTION OF URBAN RESILIENCE”, Bonn, Germany, 2019 https://e-lib.iclei.org/publications/Resilient-Cities-Thriving-Cities_The-Evolution-of-Urban-Resilience.pdf

50. Resilient Cities Network: https://resilientcitiesnetwork.org/

51. Philip Harrison, Kerry Bobbins, Christina Culwick,Tracy-Lynn Humby, Costanza La Mantia, Alison Todes and Dylan Weakley, "Urban Resilient thinking for municipalities”, University of the Witwatersrand, Gauteng City-Region Observatory, 2014, p.22

52. Davoudi Simin and Libby Porter, Applying the Resilience Perspective to Planning: Critical Thoughts from Theory and Practice, Planning Theory \& Practice, Vol. 13, No. 2, June 2012, p.306

53. Walker B., Salt D., "Resilience Thinking. Sustain Ecosystems and people in a changing world.”, Island Press, 2006

54. Fernandes José Rio, Chamusca Pedro, “Urban policies, planning and retail resilience”, ELSEVIER, 2012 p.171

55. Davoudi Simin and Libby Porter, Applying the Resilience Perspective to Planning: Critical Thoughts from Theory and Practice, Planning Theory \& Practice, Vol. 13, No. 2, June 2012, p.306

56. Walker B., Salt D., “Resilience Thinking. Sustain Ecosystems and people in a changing world.”, Island Press, 2006, pp.10- 
57. Philip Harrison, Kerry Bobbins, Christina Culwick,Tracy-Lynn Humby, Costanza La Mantia, Alison Todes and Dylan Weakley, “Urban Resilient thinking for municipalities”, University of the Witwatersrand, Gauteng City-Region Observatory, 2014, p.10

58. Martin de Jong, Simon Joss, Daan Schraven, Changjie Zhan, Margot Weijnen, “Sustainable-smart-resilient-low carboneco-knowledge cities; making sense of a multitude of concepts promoting sustainable urbanization", ELSEVIER, 2015, Journal of Cleaner Production 109 (2015) pp.25-38

59. Fernandes José Rio, Chamusca Pedro, “Urban policies, planning and retail resilience”, ELSEVIER, 2012 p.170-177.

60. Peiwen Lu, Dominic Stead, “Understanding the notion of resilience in spatial planning: A case study of Rotterdam, The Netherlands", ELSEVIER, 2013, Cities 35 (2013) 200-212

61. llgen, S.; Sengers, F.; Wardekker, A. City-To-City Learning for Urban Resilience: The Case of Water Squares in Rotterdam and Mexico City. Water 2019, 11, 983

62. Rotterdam Resilient Strategy: https://s3.eu-central-1.amazonaws.com/storage.resilientrotterdam.nl/uploads/2017/11/09115607/strategy-resilient-rotterdam.pdf

63. Peiwen Lu, Dominic Stead, “Understanding the notion of resilience in spatial planning: A case study of Rotterdam, The Netherlands", ELSEVIER, 2013, Cities 35 (2013) p.210

64. Rotterdam Resilient Strategy: https://s3.eu-central-1.amazonaws.com/storage.resilientrotterdam.nl/uploads/2017/11/09115607/strategy-resilient-rotterdam.pdf, p.14

65. Ilgen, S.; Sengers, F.; Wardekker, A. City-To-City Learning for Urban Resilience: The Case of Water Squares in Rotterdam and Mexico City. Water 2019, 11, 983

66. Peiwen Lu , Dominic Stead, “Understanding the notion of resilience in spatial planning: A case study of Rotterdam, The Netherlands", ELSEVIER, 2013, Cities 35 (2013) p.210

67. Labrianidis L. "The development path of the city since the '80s: Missing opportunities, pp.296-297, edited book “Thessaloniki in verge. The city as a transformational system", Kritiki publications, Athens, 2008

68. Pitidis Vangelis, Coaffee Jon, “Catalysing governance transformations through urban resilience implementation: The case of Thessaloniki, Greece", ELSEVIER, Cities 107 (2020) 102934

69. Resilient Cities Network: https://resilientcitiesnetwork.org/

70. Pitidis Vangelis, Coaffee Jon, “Catalysing governance transformations through urban resilience implementation: The case of Thessaloniki, Greece", ELSEVIER, Cities 107 (2020) 102934, pp.4-6

71. City of Thessaloniki, Resilient Strategy, “Thessaloniki 2030”, March 2017, www.thessaloniki.gr

72. Pitidis Vangelis, Coaffee Jon, “Catalysing governance transformations through urban resilience implementation: The case of Thessaloniki, Greece", ELSEVIER, Cities 107 (2020) 102934, pp.8

73. City of Thessaloniki, Resilient Strategy, “Thessaloniki 2030”, March 2017, www.thessaloniki.gr

74. Pitidis Vangelis, Coaffee Jon, “Catalysing governance transformations through urban resilience implementation: The case of Thessaloniki, Greece", ELSEVIER, Cities 107 (2020) 102934, pp.4

75. United societies of Balkans, 2017, https://www.usbngo.gr/en/local-actions/thessaloniki-youth-resilience-challenge

76. World Bank, 2019, https://blogs.worldbank.org/sustainablecities/thessaloniki-waterfront-revitalization-key-citys-growth

77. Salata Konstantina-Dimitra, Yiannakou Athena, “The Quest for Adaptation through Spatial Planning and EcosystemBased Tools in Resilience Strategies", SUSTAINABILITY, 2020

78. Chelleri Lorenzo, Aliaksandra Baravikova, "Understandings of urban resilience meanings and principles across Europe”, ELSEVIER, Cities 108(2020) 102985, 2020

79. Athanassiou E., Kapsali M., Karagianni M., “Green” and resilient: shaping a new identity for Thessaloniki, Conference: International Conference on Changing Cities 2: Spatial, Design, Landscape \& Socio-economic Dimensions", At: Porto Heli, Peloponnese, Greece, 2015 
80. Pitidis Vangelis, Coaffee Jon, “Catalysing governance transformations through urban resilience implementation: The case of Thessaloniki, Greece”, ELSEVIER, Cities 107 (2020) 102934, pp.11

81. Athanassiou E., Kapsali M., Karagianni M., “Green” and resilient: shaping a new identity for Thessaloniki, Conference: International Conference on Changing Cities 2: Spatial, Design, Landscape \& Socio-economic Dimensions", At: Porto Heli, Peloponnese, Greece, 2015

82. Peiwen $\mathrm{Lu}$, Dominic Stead, “Understanding the notion of resilience in spatial planning: A case study of Rotterdam, The Netherlands", ELSEVIER, 2013, Cities 35 (2013) 200-212

83. Chelleri Lorenzo, Aliaksandra Baravikova, "Understandings of urban resilience meanings and principles across Europe", ELSEVIER, Cities 108(2020) 102985, 2020 